\title{
In the
}

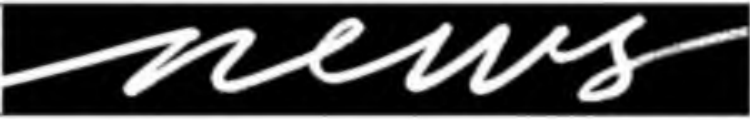

Do you remember note cards? Those cards used to copy-by hand--pertinent facts, figures, and quotes as we gathered material in support of our research papers. As much as I hated the hand-copying, the cards did force me to be selective in the information I gathered and helped me organize my thoughts prior to writing. These cards were replaced with the photocopies bearing yellow-highlighted text.

Now even photocopying is being phased out by "cut and paste." The 8th graders I work with through Girl Scouts start all research by jumping on the Web. Relevant information gets copied and pasted into a waiting Word document. Throw in a few transition sentences, paragraphs, and voilà — a finished paper!

Now Questia, an Internet start-up due to launch this month, plans to take cut and paste to the next level (see page 5). Launching with 50,000 full-text digital titles in the liberal arts, the service, marketed directly to undergradu- ates, aims to make paper writing even easier. With a Questia subscription, students can search the full-text for the pertinent phrase, copy it, and paste it with an automatically generated citation coming along with the selected text. Although Questia's goal of 250,000 books is not a huge database given the millions of items published, if I were a student I'd want a subscription to it. It will be interesting to see what impact Questia has on research papers. Will most freshman papers use only sources found in Questia? Will professors start insisting that papers contain at least three nonQuestia sources to try and vary their students' work? It has the sound of a useful tool; it will be fun to see how academe embraces it.

A special thanks to Kit Dusky for once again volunteering her time to compile an index to CERL News.

-Mary Ellen K. Davis Editor-in-chief, medavis@ala.org

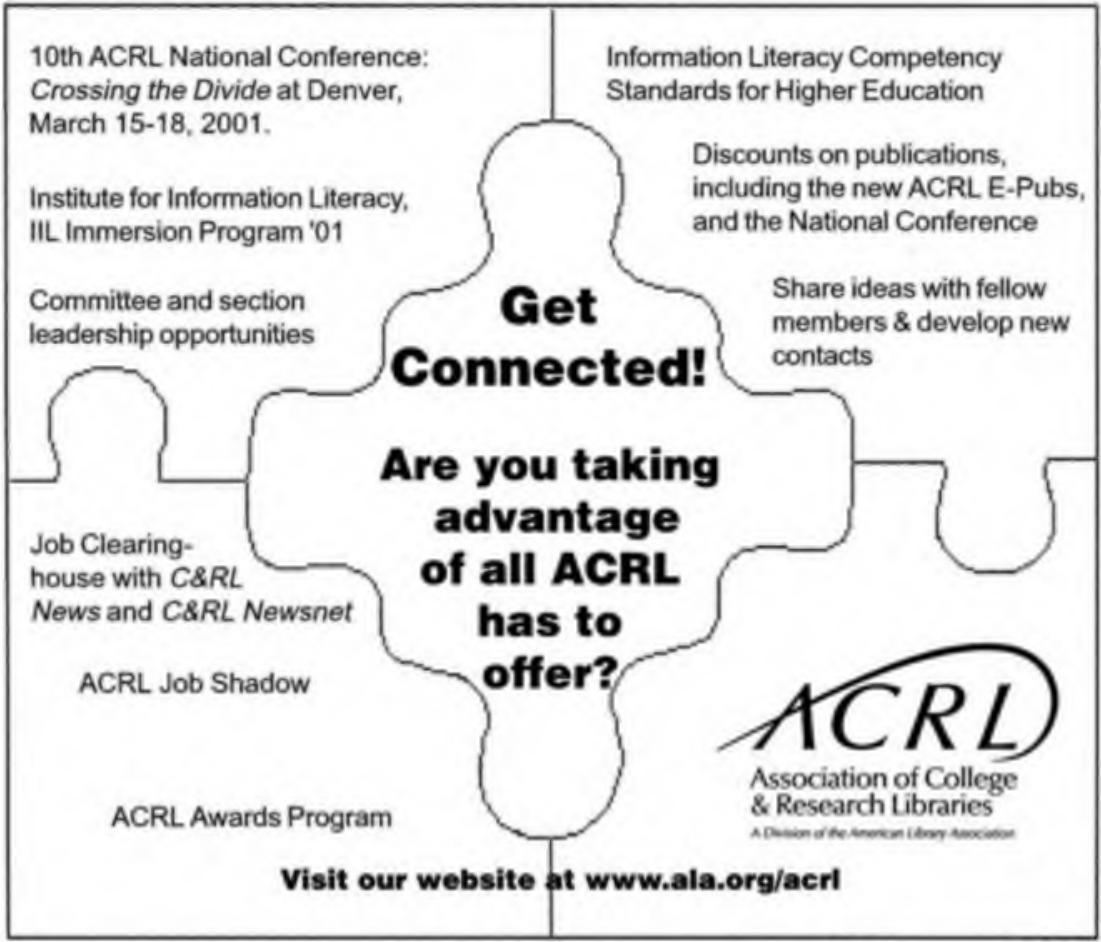

